\title{
O RAZVOJU SLOVENSKE VOJSKE
}

\section{ABOUT THE DEVELOPMENT OF THE SLOVENIAN ARMED FORCES}

Povzetek Avtor v članku pregledno obravnava nastanek in razvoj Slovenske vojske, njeno vlogo v slovenski osamosvojitvi in ob izzivih, ki nas čakajo ob vključitvi v Nato in EU. V prvem delu besedila obravnava vzroke, ki so povzročili razpad JLA in oblikovanje slovenskih oboroženih sil, njihov razvoj iz TO in MSNZ v Slovensko vojsko, v drugem pa razmišlja o reorganizaciji in profesionalizaciji Slovenske vojske ter njeni vlogi v spremenjenih varnostnih okoliščinah prihodnosti.

Ključne Varnostno okolje, splošni ljudski odpor, TO, MSNZ, sodobne oborožene sile, besede vojaški rok, profesionalizacija, prednostne naloge razvoja.

Abstract The author discusses in his article the foundation and development of the Slovenian Armed Forces, its role in the War for Slovenia and various challenges that our country has to cope with upon joining NATO and the EU. The first part of the article deals with the reasons for the disintegration of the Yugoslav People's Army and the formation of the Slovenian Armed Forces, their development from the Territorial Defence and National Defence Manoeuvre Structure to the Slovenian Armed Forces. In the second part, the author provides some reflections about the reorganization and professionalization of the Slovenian Armed Forces and its role in the altered future security situation.

Key words Security environment, general national resistance, Territorial Defence, National Defence Manoeuvre Structure, modern armed forces, military conscription, professionalization, development priorities. 


\section{VLOGA OBOROŽENIH SIL}

Clausewitzeva ugotovitev, da je vojna podaljšana roka politike in vojska njeno orodje, njeno sredstvo za doseganje političnih ciljev, je danes še kako očitna $\mathrm{v}$ razvitih demokratičnih državah. Združene države Amerike so dober primer, nekdanji predsednik združenega štaba vodi zunanjo politiko, ameriška vojska pa zagotavlja in brani ameriške zunanje interese (National Security Strategy for a Next Century - NSS, October 1998, White House, ZDA). Nič drugače ni v Ruski federaciji, Francozi, Belgijci in drugi ravnajo podobno. Dolga tradicija in relativno dolga samostojnost sta jasno oblikovali gospodarski in politični interes in temu primerno vojaško organizacijo, z jasno zapisano vizijo vojaškega razvoja in opredeljenimi nalogami. Potrebam in interesom primerno organizirajo, opremljajo, usposabljajo in uporabljajo svoje orodje - vojsko (NSS). Nekdanja skupna država Jugoslavija je pri razvoju in uporabi svoje vojske ravnala podobno. Politično vodstvo je $v$ blokovski delitvi sveta krmarilo med vzhodom in zahodom, njegov glavni cilj je bil ostati na oblasti. Temu primerno so razvijali obrambno in vojaško strategijo ter vojaško doktrino in taktiko. Kmalu po ustanovitvi države so poslali svojo vojsko na mirovno operacijo na Bližnji vzhod, kar je bilo skladno s političnimi ambicijami (pozneje neuvrščenost) in gospodarskimi interesi države (nafta). Ob spoznanju, da samo manevrski del vojske ne bo mogel obraniti države (ugotovitve iz analize češkoslovaških dogodkov 1968) in vladajočega režima, so začeli po republikah razvijati teritorialno obrambo ter koncept splošnega ljudskega odpora in družbene samozaščite (SLO in DSZ) kot dopolnilo manevrski strukturi zvezne vojske. Izkušnje pri uporabi tega koncepta so bile že bogate, na primer Vietnam in gverilske ali partizanske organizacije, na naših tleh pa smo ga preizkusili v drugi svetovni vojni. Iračani bi to trditev dopolnili, če je njihov odpor proti Američanom organiziran, kar očitno je. Srečujejo se z bolje opremljenim, usposobljenim in izurjenim nasprotnikom, ki mu poskušajo razmere za bivanje ustvariti nevzdržne in ga tako prisiliti, da zapusti državo, kar je temeljna zamisel in ideja koncepta (splošnega) ljudskega odpora.

\section{SLOVENSKA SAMOSTOJNOST IN OBOROŽENE SILE}

Slovensko politično vodstvo in slovenska politika sta uspešno uporabila Teritorialno obrambo (TO), v letu 1990 v Sloveniji najbolj razvito, ter dodatno organizirano, opremljeno in usposobljeno Manevrsko strukturo narodne zaščite (MSNZ). Brez velikih bitk, kot je bila na primer pri Kursku, vendar s spretnostjo najboljših vojskovodij, je bila dosežena slovenska samostojnost. In po Clausewitzu uporabimo vojsko in vojaško silo, ko doseganje zastavljenega političnega cilja po politični poti ni mogoče, in jo umaknemo, ko je diplomatska pot spet odprta oziroma ko je nasprotnik v položaju, da se mora (in hoče) pogovarjati na nam sprejemljiv način. Samostojnost je bila davni sen slovenskega naroda, politično vodstvo je ta cilj skušalo doseči po mirni poti, ker pa je bilo neuspešno, so TO, Policija (Milica) ter civilna obramba uspešno izpolnile svojo nalogo. 
V naši osamosvojitveni vojni so bitke in boji potekali po konceptu splošnega ljudskega odpora, z uporabo posameznih načel in prvin partizanskega bojevanja: predvsem po načelu »udari in se umakni«. Frontalne oblike oboroženega boja nismo uporabili. Številčno sicer močnejši, vendar tehnično podrejeni, bitke prsi ob prsi na odprtem prostoru nismo mogli sprejeti. Tudi večje koncentracije TO na majhnem prostoru nismo smeli uporabiti, premoč v zraku je bila prevelika. Obe strani sta spoštovali načelo minimalne uporabe sile, obema je bilo na voljo več ljudi in sredstev za vojaški spopad, kot sta jih dejansko uporabili (besede poveljnika 7. pokrajinskega štaba TO Maribor v začetku julija 1991: »Napad na sedanjo Vojašnico generala Maistra bi povzročil preveč smrtnih žrtev«). Lahka in v primerjavi z jugoslovansko armado zastarela pehotna oborožitev nam marsičesa ni omogočala, premike sovražnika smo na primer ovirali na različne načine, tudi s sredstvi iz popisa. Sestrelili smo dva helikopterja, letala pa so bolj ali manj neovirano in neopaženo letala nad našimi glavami, zračnega prostora nismo obvladovali. S pravilnimi odločitvami in s pravim občutkom za realnost smo dosegali vojaške zmage. Zmagali bi tudi, če bi preostanek Jugoslavije in jugoslovanska armada uporabila vsa razpoložljiva sredstva, gotovo pa bi to zmago plačali z več žrtvami in večjo škodo.

Republika Hrvaška se je za svojo samostojnost morala boriti nekaj let. Dolgo je organizirala, opremljala in predvsem usposabljala svojo vojaško organizacijo (ter čakala na primeren politični trenutek). Izdatki so bili neprimerljivo večji, veliko več poklicnih in rezervnih vojakov je bilo treba za oblikovanje učinkovite vojske, ki je uspela s svojega ozemlja izriniti oziroma v operaciji Nevihta premagati (krajinsko) srbsko (jugoslovansko) armado. Uresničitev zastavljenega cilja, samostojnosti in suverenosti ali vojaškopolitične zmage, pa v večini primerov odpira vprašanje prevelike (v minuli vojni sicer nujne) in za neko prihodnjo vojno neustrezno organizirane vojske. Večina držav, tudi Slovenija, se je po vojni srečala z zmanjšanjem obrambnih izdatkov, odpuščanjem oziroma demobilizacijo vojske in modernizacijo. Mnoge države se ukvarjajo s socialnimi problemi in različnimi sindromi, ki so posledica oboroženih bojev (Vietnam, Irak 1991, Kosovo). Posamezne države in oborožene sile so to vprašanje reševale vsaka na svoj način, drugače od drugih. Samo Slovenija pa je po vojaški zmagi začela graditi svojo vojsko.

\section{SPREMEMBE VARNOSTNEGA OKOLJA}

Po padcu berlinskega zidu so se varnostne razmere v svetu zelo hitro spreminjale. Nevarnost jedrskega spopada svetovnih razsežnosti se je zmanjšala, gospodarsko in vojaško tekmovanje je preživela le ena svetovna sila, globalizem je prinesel skoraj trenutne povezave in obilje informacij o dogajanju v svetu, zelo se je razvil organiziran kriminal, pojavil se je terorizem. Delitev sveta se je, če priznamo ali ne, začela tudi po verskem prepričanju, Kitajska bo s svojo ekonomsko rastjo in vesoljskimi poleti začela uveljavljati vse večji politični vpliv. Zelo verjetno se bo v »nezanesljivi prihodnosti« (Preparing for an Uncertain Future, NSS) oblikovalo več različnih regionalnih centrov gospodarske, politične in vojaške moči. V blokovski delitvi sveta je bilo popolnoma jasno, kdo in kje je nasprotnik, nenadoma pa 
tradicionalnega, klasičnega nasprotnika ni lahko identificirati. Stvarni in zaznani občutek naše varnosti sta se s prepričanostjo, da vojna v evropsko-ameriškem prostoru ni več mogoča oziroma da je malo verjetna, zelo povečala. Zmanjšuje se občutek vojaške ogroženosti, povečuje pa zaznavanje ogroženosti zaradi mednarodnega terorizma, organiziranega kriminala ...

Že v letih 1995 in 1996 je bilo vojaško in varnostno okolje za Slovenijo zelo spremenjeno. Do takrat smo poslušali streljanje na fronti v Karlovcu, samo lučaj od naše državne meje v Beli krajini, in gledali posnetke grozot iz Bosne in Hercegovine $(\mathrm{BiH})$, navsezadnje smo imeli tudi veliko število beguncev iz teh republik in smo vsak dan poslušali opise bojev na domnevnih vojaških frontah. Tudi mi smo se še počutili vojaško ogroženi. Oddahnili smo si, ko sta se vojna in nam osovražena armada po hrvaški operaciji Nevihta preselili daleč od naših meja, ni pa nam bilo vseeno za strahote, ki so se dogajale, in umiranje prebivalcev BiH, ki so bili še zmeraj v vojni. UNPROFOR (United Nations Protection Force), pozneje SFOR (Stabilization Force) je tudi nam zmanjšal občutek ogroženosti in povečal dejansko in zaznavno varnost. V letu 1997 smo mednarodnim enotam v BiH tudi sami prispevali letalskohelikopterski oddelek, ki naj bi pomagal zagotavljati mir v tej regiji. Za to dejanje smo imeli najmanj dva razloga, želeli smo mir v sosednjih državah, na $\mathrm{BiH}$ pa nas veže tudi izrazit gospodarski interes, zato smo s to regijo oziroma državo želeli nadaljevati gospodarsko in druge oblike sodelovanja.

Leta 1997 se je "porušila« albanska država; veliko Albancev živi v Sloveniji in zato so razmere v Albaniji spreminjale tudi našo varnostno situacijo. Z mednarodno skupnostjo smo sodelovali pri vzpostavljanju miru in obnovi države, hoteli smo biti del skupnosti, ki ji ni vseeno za mir v tem delu sveta in v tej regiji, posredno pa smo želeli ščititi tudi naše gospodarske interese. Vse v vojno na balkanskih bojiščih vpletene strani so uporabljale koncept splošnega ljudskega odpora. Poznavalcu ni bilo težko prepoznati kar celih odstavkov Strategije splošnega ljudskega odpora in družbene samozaščite ter Strategije oboroženega boja. Vsa sredstva in posamezniki, v civilu ali uniformi, vse je bilo uporabljeno v teh bitkah. Kdor ni bil »z nami«, je bil »proti nam« in ga je bilo treba v poduk drugim pravočasno umakniti. Podobno taktiko je mogoče opaziti v Iraku, likvidacija »domačih izdajalcev, ki sodelujejo z okupatorjem«, ni v svetu nič neznanega. Ljudi je treba prestrašiti, da bodo z nami, ali pa vsaj ne bodo sodelovali z okupacijsko vojsko. Vojakova dolžnost je pasti za domovino, posameznik ne šteje veliko. Posledice takega koncepta vojne smo čutili in čutimo v obliki beguncev tudi v Sloveniji, število mrtvih se meri v tisočih, desetin stotisočih. Nihče ni prešteval ranjenih, poškodovanih in človeških razvalin ter razbitih družin, nastalih zaradi duševnih pretresov. Pri uporabi koncepta »vsi smo mi vojska« je pojav vojaških zločinov več kot očiten, rane v človeških dušah se zelo težko zacelijo in tudi če se, so brazgotine velike in še dolgo opazne. Mar nismo že kar prepričani, da bodo Srbi in kosovski Albanci zelo težko živeli pod isto streho?

Poznamo dve vrsti varnosti, navidezno ali zaznano, ki nam daje občutek, da živimo v varnem okolju (ogroženost pred vojno, pred naravnimi in drugimi nesrečami, 
ogroženost delovnega mesta, socialna varnost ...), in dejansko oziroma stvarno, ki nam govori o resničnem vojaškem ogrožanju z vojno, terorizmom, orožji in sredstvi za množično uničevanje, organiziranim kriminalom ... V vsej vojaški zgodovini sveta poskušajo vojaški in vojaškopolitični strategi pri morebitnem ali dejanskem nasprotniku vzbuditi vtis navidezne varnosti, da bi dosegli strateško presenečenje in lažje vojaške (in politične) zmage. Pakt o nenapadanju med nacistično Nemčijo in Stalinovo Sovjetsko zvezo je lep primer zavajanja nasprotnika. Danes se v naši državi počutimo veliko varneje kot pred leti. Skoraj ne vidimo nasprotnika, ki bi nas lahko vojaško napadel, srečujemo pa se z različnimi drugimi oblikami nevojaškega ogrožanja (potrjene v Državnem zboru in zapisane v Resoluciji o strategiji nacionalne varnosti RS, Uradni list RS, št. 56/01). Gotovo pa bomo gospodarsko, politično in kulturno uspešnejši, dosegali bomo višjo kvaliteto življenja, če bosta mir in stabilnost doma, v ožjem in širšem sosedstvu ter v svetu. Miru in stabilnosti pa ne moremo zagotavljati in zagotoviti sami, izolirani od sveta, to lahko dosežemo le skupaj z vso demokratično mednarodno skupnostjo.

Dobili smo vabilo za polnopravno članstvo v severnoatlantskem zavezništvu, od maja prihodnjega leta bomo polnopravni člani Nata in EU. Ne gre zgolj in samo za vabilo, v ta krog držav smo sami želeli, spoznali smo, da imamo s članicami zavezništva in Unije veliko skupnih interesov, da bomo na ta način vsi veliko pridobili ter da bomo laže delovali na političnem, gospodarskem in obrambno-varnostnem področju. Verjetnost, da bi nas kdo klasično vojaško ogrožal, postaja tako še manjša, občutek varnosti pa vse večji. Večina državljank in državljanov je že pozabila, da smo se komaj pred dvanajstimi leti borili za svojo samostojnost, razmer druge svetovne vojne pa se spominjajo vse bolj redki posamezniki, omenjajo jih le še zgodovinski učbeniki, vse težje pa si predstavljamo, da so tisoči slovenskih mladeničev umirali na soški in drugih frontah prve svetovne vojne. Za mir se je vredno in treba boriti, varnost je treba nekako plačati. »Vojska da, toda brez mene« je stališče, ki je precej razširjeno po Evropi, potrjeno v zadnjih raziskavah avstrijskih kolegov o odnosu civilnega prebivalstva do vojske in vojaškega poklica (okrogla miza Mladi in vojaški poklic, september 2003, Gornja Radgona). Če smo se v miru pripravljali na vojno, moramo naše stališče in misli usmeriti k pripravam v miru za zagotavljanje miru (»Si vis pacem, para pacem«, gen. Manfred Eisele, pomočnik generalnega sekretarja Združenih narodov za mirovne operacije, Celje, september 2003).

\section{ISKANJE ODGOVOROV}

Teritorialno obrambo smo razvijali za obrambo v Sloveniji in znotraj njenih meja. Posebno poglavje v naši zgodovini predstavljata razvoj Manevrske strukture narodne zaščite in njena izjemna vloga $\mathrm{v}$ pripravah in procesu osamosvajanja od maja do oktobra 1990. Zaradi namena (in načina podpore delovanja ter predvsem zaledne oziroma logistične zagotovitve) enote TO niso mogle opravljati vojaških akcij zunaj naših meja. Te enote niso mogle izvajati ofenzivnega, predvsem napadnega delovanja večjih razsežnosti. Maloštevilna stalna sestava je bila razporejena po občinskih in pokrajinskih štabih. V osnovni zamisli oblikovanja in organiziranja je imela teritorialna obramba 
s svojimi enotami predvsem dopolnilne naloge (obramba medprostorov, posameznih objektov, diverzantske in protidiverzantske naloge na začasno zasedenem ozemlju, naloge pokrivanja terena) v sodelovanju z zvezno vojsko. Občinski sekretariati so skrbeli za popise vojaških obveznikov, napotitve na služenje vojaškega roka, popis sredstev, popolnitev štabov in enot. Vsak posameznik moškega spola se je po sili zakona v določeni starosti pač moral javiti na določen naslov; določene so bile sankcije za nespoštovanje veljavnega zakona, ki so se tudi izvajale. Usposabljanje vojakov nabornikov je izvajala jugoslovanska vojska, ki je pomagala tudi pri usposabljanju enot TO. Poveljniki so bili zadolženi za usposobljenost svojih enot. Štabi TO so bili podrejeni Republiškemu štabu za TO in Republiki Sloveniji, usposobljenost in priprave za obrambo pa je preverjala tudi zvezna inšpekcija za obrambo. Odločenost, pogum in ustrezno vodenje obrambne strukture so bili kronani z vojaško zmago.

Neposredno pred vojno, še izraziteje pa po zmagi in osamosvojitvi, smo začeli sami opravljati naloge, ki pripadajo samostojni državi in njeni obrambni strukturi. Skrb za vojaško obrambo države je prevzela teritorialna obramba, opremljena z izrazito lahko oborožitvijo in opremo, zaseženo v vojni in iz popisa, organizirana in usposobljena po konceptu SLO. Drugače od drugih držav smo po vojaški zmagi in osamosvojitvi šele začeli graditi novo vojsko. Pri začetku njenega uresničevanja sta bila upoštevana dva temeljna elementa: najprej zgodovinska izkušnja pravkar minule desetdnevne vojne in seveda sovražnik oziroma nasprotnik, ki je še zmeraj nosil isto ime. Ogroženi smo se počutili doma, v svoji državi. Pripravljali smo se na obrambo na svojem ozemlju, proti znanemu nasprotniku in s svojim znanjem (skladno s konceptom SLO) smo lahko postavili samo podobno vojsko, kot smo jo že poznali. Z današnjega zornega kota gledano smo se pripravljali na vojno, ki smo jo že dobili.

V našem znanju in v novi vojaški organizaciji je manjkal marsikateri element obrambe, marsikatera komponenta vojaške moči ni bila upoštevana. Edina manevrska enota takratne vojske je bila pravzaprav brigada Moris; nastajali pa so elementi nadzora zračnega prostora, zračne obrambe, letalstva, mornarice, inženirstva, RKBO in vojaške policije. Popolnjevanje enot je potekalo po podobnem teritorialnem principu kot pred osamosvojitveno vojno in zaradi tega ter zaradi odvisnosti zaledne zagotovitve od civilne obrambe so tudi potencialno manevrske enote (na primer bataljon radiološko-kemične in biološke obrambe) postale zelo odvisne od lokalne popolnitve in tako nepremične in izrazito vezane na eno lokacijo. Znanje angleščine (predvsem specifičnih angleških vojaških izrazov) in povezljivost z drugimi vojskami sta bila kritična. Samo 15. brigada vojnega letalstva je od nastanka pri usposabljanju uporabljala angleščino in mednarodne zahteve (ICAO), popolnjena je bila s poklicno sestavo in zato smo lahko začeli mednarodno sodelovanje na enem najbolj zahtevnih področij povezljivosti. Edina nova (vojaška) naloga, ki smo se je temeljiteje lotili, je bila postavitev sistema služenja vojaškega roka in usposabljanja vojaških obveznikov za vojaško obrambo ter službo v obvezni rezervi. To usposabljanje smo leta 1994 zapisali v 37. člen Zakona o obrambi (Uradni list RS, št. 82/94) kot prvo nalogo, ki jo moramo opraviti. Njeno uresničevanje je omogočalo popolnjevanje številčno velike vojne strukture takratne vojske. 
Zmotna je misel, da obrambo po konceptu splošnega ljudskega odpora zagotavljajo vojaki naborniki, ti se usposabljajo predvsem za službo v vojni sestavi (dikcija 37. člena Zakona o obrambi: »... in usposabljanje za oborožen boj in druge oblike vojaške obrambe«), s katero vojska brani našo suverenost. To se je jasno videlo že na začetku te naloge, že prve generacije naših nabornikov v Pekrah in na Igu nismo izpostavljali ali pošiljali v vojaški spopad, nasprotno, pred jugoslovansko armado smo jih branili in varovali z rezervno sestavo (primer napada na Pekre, maj 1991). Z opustitvijo služenja vojaškega roka nismo neposredno zmanjšali naših zmožnosti za obrambo oziroma bojne pripravljenosti ali pripravljenosti vojske za bojevanje. Dolgoročno, po desetih ali dvajsetih letih, bi to seveda vplivalo tako, da za popolnitev vojnih enot ne bi imeli dovolj usposobljenih pripadnikov rezervne sestave, če koncepta vojaške obrambe ne bi spreminjali.

V kratkem času, preko noči, nismo uspeli usposobiti dovolj novih podčastnikov in častnikov za vodenje vojske, ki je narasla na približno 80000 pripadnikov. Za poveljevanje takšni vojski smo zaposlovali veliko častnikov in podčastnikov iz rezervne sestave, jih usposabljali za vodenje in jih poviševali v višje čine. Potrebovali smo poklicni kader za vodenje enot, popolnjenih z obvezno rezervo, in za usposabljanje nabornikov. Stalna sestava Slovenske vojske se je povečala na račun novozaposlenih poveljnikov oddelkov (podčastniki), vodov, čet, učnih centrov in bataljonov (častniki) za izvajanje usposabljanja ter podčastnikov in častnikov poveljstev vseh ravni.

$\mathrm{V}$ času, ko smo zaznavali in čutili ogroženost miru in stabilnosti predvsem v ostankih nekdanje Jugoslavije, smo razvijali vojaško organizacijo, ki je z izkušnjami in vojno dokazala, da se proti taki nevarnosti zna boriti. S pomočjo Zakona o zagotavljanju sredstev za realizacijo temeljnih razvojnih programov obrambnih sil RS v letih 1994-2003 (Uradni list RS, št. 13/94) in financiranjem iz rednega proračuna smo poskušali opremiti, organizirati in usposobiti vojsko, sposobno samostojne obrambe naše suverenosti in nedotakljivosti. Teritorialno obrambo in od leta 1994 Slovensko vojsko sta odlikovali predvsem množičnost in uravnotežena razvitost (organizacijsko-mobilizacijski razvoj) v vseh delih naše države. Infrastrukturo, namenjeno naborniški vojski in prilagojeno takšnemu organizacijsko-mobilizacijskemu razvoju, nam je zapustila že jugoslovanska vojska, veliko objektov te infrastrukture (kadetnica v Mariboru, vojašnica v Bohinjski Beli, letališče v Cerkljah) pa je bilo tudi že pred drugo svetovno vojno. Vojaško organizacijo kot nosilca vojaške obrambe smo vzpostavili skupaj s civilno obrambo in prilagodili naborniškem sistemu. S služenjem vojaškega roka smo skoraj vso moško populacijo države usposabljali za opravljanje različnih vojaških nalog v vojni. Še danes je več kot deset odstotkov prebivalstva usposobljenih (se je usposabljalo) za različne oblike vojaške obrambe na domačem ozemlju. Stalna in rezervna sestava TO in pozneje Slovenske vojske sta številčno rasli, od 369 zaposlenih v Republiškem sekretariatu za ljudsko obrambo konec junija 1991 je stalna sestava narasla na približno 4000 pripadnikov. Vodilni del vojske so predstavljali predvsem častniki, usposobljeni na šolah za rezervne oficirje $\mathrm{v}$ 
jugoslovanski vojski, ki so se pozneje kalili v osamosvojitveni vojni. Z začetkom sodelovanja $\mathrm{v}$ mirovnih operacijah so se pojavili novi izzivi in nova vprašanja, na katera smo morali poiskati ustrezne odgovore. Sodelovanje letalsko-helikopterskega oddelka v mirovni misiji ni predstavljalo večje težave, ta enota svojo nalogo v mirovni operaciji brez nesreč opravlja že več kot šest let. Težava pa se je pojavila z naslednjimi operacijami, saj nismo imeli primerne enote ali usposobljenega zadostnega števila vojakov ali posameznikov, ki bi jih lahko oblikovali kot enoto in poslali na vojaško (mirovno) operacijo v tujino. Posameznike za misije in operacije smo zbirali v vsej Slovenski vojski. Še težje je bilo za vojaške vaje zbrati ustrezno opremo in sredstva iz popisa; svojih nismo imeli dovolj, gospodarstvu pa jih je bilo iz upravičenih razlogov še težje jemati. V slovenskem prostoru nikoli ni bilo težko dobiti sredstev za obrambo domovine, za »pravo stvar«, v miru pa je za usposabljanje iz razumljivih vzrokov (pridobitna dejavnost lastnikov) to postajalo vse težje. Zaradi rastočih zahtev v mednarodnem sodelovanju je nastal bataljon (sedaj 10.) za mednarodno vojaško (mirovno) sodelovanje, ki naj bi bil popolnjen samo s poklicno sestavo. Na upočasnjeno popolnjevanje, opremljanje in razvoj tega bataljona je verjetno vplivalo tudi to, da Slovenija v Nato ni bila povabljena v prvem krogu širitve. Pomembno pa je, da smo začeli spoznavati, da potrebujemo enote, popolnjene s poklicno sestavo.

\section{POLNOPRAVNO ČLANSTVO V NATU IN EU}

Po prvem krogu širitve Nata, ko je tudi Madžarska postala polnopravna članica, po vse boljših vojaških odnosih z Republiko Avstrijo in Republiko Italijo ter po spremembi razmer jugovzhodno od Slovenije je postal varnostni položaj Republike Slovenije bistveno ugodnejši. Politični režimi v regiji so se spreminjali, jugoslovanski predsednik Milošević je po vojaškem porazu leta 1999 izgubil svojo vojaško moč. Vojaško sodelovanje Slovenske vojske kot nadaljevanje zelo dobrih gospodarskih in političnih odnosov s sosedi, drugimi evropskimi državami in ZDA se je poglobilo. Analize slovenskega javnega mnenja kažejo, da se je občutek varnosti državljanov in državljank povečal (poročilo raziskovalnega projekta Stališče slovenske mladine do vojaškega poklica 2003, primerjava rezultatov iz let 1990, 1991, 1994 in 1995, Fakulteta za družbene vede, Obramboslovni raziskovalni center, Ljubljana, september 2003). Vojaška moč Slovenske vojske se je krepila, vojska je v tem času intenzivno uvajala standarde posameznih evropskih vojsk, povezljivost je postajala vse pomembnejša. Vse pogostejše skupne vaje in usposabljanja z državami članicami Partnerstva za mir in severnoatlantskega zavezništva so dokaz, da se zmoremo bojevati z ramo ob rami s temi vojskami.

$\mathrm{V}$ tem času se je postopoma večalo tudi število naših pripadnikov v mirovnih operacijah ter število vojaških predstavnikov v tujini. Izrazito se je večalo tudi število častnikov in podčastnikov, ki so pridobivali novo vojaško znanje v tujini, na skupnih usposabljanjih in vajah ter na najvišjih vojaških šolah. Izkušnje in obseg ter kvaliteta našega znanja so se postopoma širili. Novembra 2002 smo dobili vabilo za članstvo v Natu. Na referendumu smo se z dvotretjinsko večino odločili 
zanj. Tako smo dodatno okrepili in utrdili svoj obrambno-varnostni položaj, hkrati pa se tudi zavezali, da bomo obrambne zadeve reševali skupaj in v korist vsega severnoatlantskega zavezništva. Odnos je korekten - mi pomagamo zavezništvu, oni pomagajo nam; oblika in količina pomoči pa sta stvar pogajanj. Tudi mi smo postali zavezništvo.

\section{ZNAČILNOSTI PRIHODNJIH VOJAŠKIH OPERACIJ}

Vojne v nekdanji Jugoslaviji in v svetu (Kosovo leta 1999, Afganistan, letos Irak, liberijski dogodki) nam nakazujejo smer in razvoj svetovnih dogodkov ter smer in značaj prihodnjih vojaških operacij. Možnost vojaškega spopada doma ali v bližnji okolici seveda ostaja, verjetnost, da do njega dejansko pride, pa je zelo majhna. Razvoj globalizacije in vse močnejše težnje po razvoju skupnih regionalnih večnacionalnih vojaških enot nas vodijo v sklep, da bomo vojaške naloge opravljali večinoma zunaj Slovenije, skupaj z našimi zavezniki in prijatelji. Vse izrazitejše je stališče, da je treba vojaške spopade, napetosti in ogrožanja preprečevati oziroma jih pomagati reševati še preden se razvijejo v resen meddržavni, medetnični ali kakšen drug konflikt in preden dosežejo meje lastne države ter ogrozijo njeno varnost, stabilnost, socialni mir in gospodarski razvoj. Cena, izražena s številom mrtvih, ranjenih in poškodovanih, cena gospodarske obnove in obnove infrastrukture je neprimerljivo manjša, kot je soočenje z virom ali posledico ogrožanja na meji. Sodobne oborožene sile so izrazito dobro opremljene, organizirane, usposobljene ter predvsem logistično samostojne (po načelih premičnosti, premestljivosti, vzdržljivosti, zaščite sil, povezljivosti in združljivosti) in zahtevajo dobro podporo bojnega delovanja ter bojno podporo (Combat Support, Combat Service Support). Sestavljajo jih zavezniške enote (trajnejša organizacija) ali enote koalicije za opravljanje enkratne vojaške naloge. Države, z izjemo velikih, razvijajo le posamezne komponente ali specialnosti oboroženih sil. V Evropi (tudi z Nato Reaction Force) so težnje razvoja in združevanja sil zelo izrazite, imajo svojo tradicijo. Po nastanku Nata se je na primer najprej združila zračna obramba držav članic, sledile so posamezne mornariške povezave in združitve (Nizozemska, Belgija), sedaj se združujejo tudi večje kopenske enote.

Sodobna vojaška oprema, zahtevana visoka izurjenost in usposobljenost posameznika in enote ter hiter tempo vseh vrst sodobnih vojaških operacij zahtevajo daljše usposabljanje vojakov, podčastnikov in častnikov ter enot. Nabornika je med kratkim služenjem vojaškega roka (v Sloveniji sedem mesecev) za takšno bojevanje nemogoče usposobiti. Neusposobljen vojak na bojišču ogroža samega sebe, svoje tovariše, enoto in je lahek plen za nasprotnika. V mornarici in letalstvu so se s podobnimi težavami (zahtevnost opreme in usposabljanja, visoka usklajenost delovanja) srečali že pred desetletji, zato je dele teh vojaških zvrsti profesionalizacija zajela že veliko prej; sodobna kopenska oprema pa te korake narekuje tudi za kopensko vojsko. Kopenska vojska (Land Force) je v večini držav najštevilčnejša, zato je proces profesionalizacije teh delov vojske tudi najbolj boleč (izkušnja španskih oboroženih sil; Major General Felix Lanz Roldan, 
junij 2003). Cilj sodobnega, dobro opremljenega in izurjenega vojaka je opraviti nalogo ter preživeti na bojišču, sam in s tovariši. Slabo opremljen, neizurjen vojak in neusposobljena enota imata zelo malo možnosti za preživetje; slabo ali pomanjkljivo usposabljanje različnih enot znotraj ene vojske ali višje enote in pomanjkanje usposabljanja zavezniških ali koalicijskih enot pa zmanjšujeta učinke bojevanja in povečujeta možnosti napak in odpiranja prijateljskega ognja (znani primeri iz Afganistana: ameriška letala so delovala po Kanadčanih, v Iraku zabeleženo še več primerov).

V Slovenski vojski smo spremljali razvoj in predvidevali takšno vrsto sodobnega bojišča. Jasno nam je, da moramo organizirati, opremiti in usposobiti vojsko za izvajanje nalog doma in $\mathrm{v}$ tujini, samostojno ter $\mathrm{v}$ sodelovanju $\mathrm{z}$ zavezniki in prijatelji. Da bi to dosegli, smo sodelovali pri pripravi strateškega pregleda obrambe, pripravili smo osnutek splošnega dolgoročnega plana razvoja in opremljanja SV. Namen, cilj (tudi) vojaške obrambe je »odvračanje napada na državo ter obramba neodvisnosti, nedotakljivosti in celovitosti države ... tudi z vključevanjem in $\mathrm{z}$ aktivnim sodelovanjem v mednarodnih varnostnih povezavah« (2. člen Zakona o obrambi). Z majhno, moderno opremljeno, odlično usposobljeno in učinkovito vojsko ter s kolektivno obrambo bomo dosegli zastavljeni cilj. S profesionalizacijo SV, približevanjem zavezniškim strukturam, vključitvijo vanje ter preoblikovanjem gradimo vojsko, sposobno odgovoriti novim varnostnim izzivom prihodnosti.

\section{STANJE V SLOVENSKI VOJSKI}

Leto 2002 smo dočakali s 76000 pripadniki vojne sestave, organiziranimi predvsem znotraj treh operativnih poveljstev ter Prve brigade Slovenske vojske. S Konceptom SV 2004 in Obrambno strategijo RS (Vlada RS, št. 820-00/2001, december 2001) smo načrtovali postavitev enega samega operativnega poveljstva in številčno zmanjšanje vojne sestave. Verjetnost vojaškega ogrožanja države je bila v tem letu bistveno manjša kot pred desetimi leti, rast bruto domačega proizvoda je bila na visoki ravni, nad tremi odstotki, s programom partnerstva za mir ter z dvo- in večstranskim sodelovanjem s tujimi vojskami pa smo postajali vse bolj povezljivi z drugimi državami. Imeli smo svoje partnerske cilje (Partnership goals), ki so nam omogočali prva vedenja o tem, kako moramo biti opremljeni ter usposobljeni za skupne mirovne in druge zavezniške operacije. Pričakovali smo drugi krog širitve Nata in bili prepričani, da bomo vanj tudi povabljeni. Za sodelovanje v mirovni operaciji v Albaniji (1997) smo prvič uporabili neke vrste pogodbeno rezervo, ki je zelo dobro opravila svojo nalogo. V BiH smo leta 2002 v okviru SFOR-ja sodelovali z vodom vojaške policije (vod smo oblikovali z zbiranjem vojaških policistov, ki so se odločali prostovoljno) ter z medicinsko enoto (ROLE), sestavljeno iz vojaškega medicinskega osebja in osebja po pogodbi. Posamezniki so bili vključeni tudi v druge mirovne misije. 15. BRVL je nadaljevala svojo nalogo v SFOR-ju. Kljub velikemu številu pripadnikov še vedno nismo imeli enote, ki bi se lahko kot celota vključevala v tovrstne dejavnosti. 
Z Italijani in Madžari smo v tem letu že imeli sporazum o oblikovanju skupne enote v velikosti brigade (t. i. MLF, Multinational Land Force), ki bi opravljala naloge pod okriljem Združenih narodov ali Nata. Naš prispevek tej enoti znaša en bataljon; skupne vaje in usposabljanje te enote pa so redna dejavnost treh vojsk.

Usposabljanje številčno velike vojne sestave je bilo posebno poglavje. Z vojaškim proračunom, ki je bil celo blizu enega odstotka BDP, in z vse večjim obsegom operacij v tujini je bilo vse teže usposabljati rezervno sestavo na način, ki bi omogočal visoko pripravljenost za bojevanje. Srečali smo se s pomanjkanjem sredstev, z vse manjšim odzivom na usposabljanjein z zavestjo, da ogroženost države ni tako velika, da bi celotna vojna sestava morala biti enako pripravljena za bojevanje.

Varovanju objektov smo še posebej po kraji orožja v Postojni posvečali veliko pozornost, tako organizacijsko kot tehnično. Začeli smo ga izvajati tudi s stalno sestavo Slovenske vojske, klasično stražarsko službo pa so še naprej opravljali vojaki naborniki. Do 500 vojakov nabornikov ter podčastnikov in častnikov je bilo hkrati angažiranih pri varovanju.

Usposabljanje vojakov nabornikov je potekalo na 18 lokacijah po vsej Sloveniji. Izvajali smo štiri letne vpoklice. Velikosti kontingentov so bile take, da smo v tretji fazi usposabljanja popolnjevali logistične enote vojašnic in nekatere bojne enote ter seveda gardni bataljon oziroma našo protokolarno enoto. V tem letu je že več kot polovica vojakov opravljala pomožne dejavnosti v Slovenski vojski, drugi del pa je izvajal naloge pripravljenih ter intervencijskih sil. Zaradi takega načina dela je bila večina stalne sestave angažirana pri usposabljanju vojakov nabornikov. Tipičen bataljon Slovenske vojske je štel od 60 do 100 pripadnikov stalne sestave, večinoma podčastnikov in častnikov, redko tudi poklicnih vojakov.

Ugotovimo lahko, da se je del stalne sestave ukvarjal z vojaki naborniki, drugi del pa je dejansko izvajal že tretje preoblikovanje Slovenske vojske. S tem preoblikovanjem smo delno, vendar neznatno zmanjšali vojno sestavo, prepodredili posamezne enote in poveljstva, prerazporedili del kadrov, bistvenih izboljšav, predvsem na področju usposobljenosti celotne sestave, pa nismo dosegli. Oblikovali smo tri operativna poveljstva (vzhod in zahod, drugo in tretje, z osnovno nalogo usposabljanja stalne sestave, vojakov nabornikov in rezervne sestave, ter prvo, namenjeno nadzoru zračnega prostora, zračni obrambi in letalstvu, predvsem helikopterskim nalogam) ter prvo brigado, ki je bila namenjena vodenju vseh mednarodnih operacij in misij v tujini. Možnosti pri sprejemanju posameznih standardov oziroma partnerskih ciljev, katerih del so določeni standardi, so bile tako zelo majhne. Resnično težko se je hkrati ukvarjati z usposabljanjem nabornikov, z varovanjem in vzdrževanjem infrastrukture, $\mathrm{z}$ usposabljanjem obvezne rezerve ter $\mathrm{z}$ izvajanjem posameznih nalog po določenih, za nas novih standardih opremljanja in delovanja ter z njihovo vgradnjo $\mathrm{v}$ redno delo. Vse naloge ne morejo biti opravljene $\mathrm{z}$ enako prioriteto in enako kakovostno, posledice so bile opazne. Spoznavali smo, da bomo morali 
postaviti drugačno vojsko na drugačni podlagi, ki ji bomo lahko omogočili pogoje za dobro delo in s katero bomo postali učinkovitejši in sposobnejši.

Dopolnila in spremembe zakona o obrambi (Uradni list RS, št. 47/02 in 67/02) ter Dopolnila in spremembe zakona o vojaški dolžnosti (Uradni list RS, št. 86/02) so omogočila začetek profesionalizacije. Te spremembe so nastale kot posledica presoje varnostnih razmer, analize stanja Slovenske vojske (in obrambnega sistema) ter izkušenj iz mednarodnih operacij in mirovnih misij v letih 2000, 2001 in v začetku 2002. Ena od ključnih zadev navedenih sprememb in dopolnil je zakonska obveza, da s služenjem v obvezni rezervi Slovenske vojske prenehamo do leta 2010 in da zadnjo napotitev na služenje vojaškega roka opravimo najpozneje do 30. junija 2004. Druga dva ključna dokumenta je sprejela Vlada RS (Sklep o spremembah in dopolnitvah sistema popolnjevanja SV in Sklep o projekciji obrambnih izdatkov za obdobje 2002 do 2010; april, maj in junij 2002). Nanašala sta se na popolnitev SV oziroma zaposlovanje. S temi sklepi nam je vlada omogočila zaposlovanje novih poklicnih vojakov in pogodbenih rezervistov. Neposredna posledica teh sklepov (novo zaposlovanje in intenzivno usposabljanje) je bilo povečanje vojaškega kontingenta $\mathrm{v}$ $\mathrm{BiH}$ v začetku letošnjega leta, in sicer za motorizirano četo. Motorizirana četa je bila opremljena, usposobljena in preverjena po Natovi metodologiji.

Sprejeta dopolnila in spremembe obeh zakonov so zahtevali takojšnjo temeljito analizo stanja ter podrobno načrtovanje naslednjih možnih korakov in različic dogodkov ter scenarijev razvoja situacije. Analize so pokazale, da moramo pospešeno in prednostno razvijati določene vojaške enote, popolnjene predvsem s poklicnimi pripadniki, ter da moramo enako prednostno in pospešeno urejati področje, povezano z varovanjem opreme, oborožitve in objektov. Ugotavljali smo, da popolnjenost enot z obvezno rezervo, poklicnimi vojaki in naborniki na usposabljanju ne more dati zadovoljivih rezultatov. Morali smo izoblikovati pogoje, pod katerimi bo opustitev vpoklica vojakov nabornikov tudi zakonsko uresničljiva oziroma da bodo vpoklici načrtovani na način, ki v trenutku sprejemanja odločitve o opustitvi služenja vojaškega roka ne bo povzročil razlik in morebitnih krivic med posameznimi generacijami in naborniki ene generacije oziroma enega vpoklica. Pri posameznem vpoklicu smo začeli načrtno zmanjševati število vpoklicanih, julijski vpoklic nabornikov 2003 pa smo preskočili.

\section{DOSEGANJE IN IZPOLNJEVANJE POGOJEV ZA OPUSTITEV SLUŽENJA VOJAŠKEGA ROKA}

Generalštab je septembra letos ponovno analiziral stanje in naloge Slovenske vojske v letih do 2010, ko preneha zakonska obveza popolnjevanja vojne sestave z obvezno rezervo, pogoje za delovanje in izpolnjevanje z Zakonom o obrambi določenih nalog v sedanjem in prihodnjem obdobju, pogoje za delovanje Slovenske vojske v prihodnjem srednjeročnem obdobju, analiziral je spremembe v varnostnem okolju. Dodaten element analize je bilo doseganje ciljev ponudbe sil zavezništva, ki je nastala kot rezultat naših dogovorov in pogajanj z zavezništvom. Ugotovili smo, da 
nadaljnje služenje vojaškega roka v miru ni več potrebno ter da so izpolnjeni pogoji za prenehanje tega služenja. Samostojno ali skupaj z upravnim delom Ministrstva za obrambo smo v tem času izvedli naslednje ukrepe za omogočanje prehoda na poklicno vojsko, dopolnjeno s pogodbeno rezervo:

- pripravili smo spremembe normativnih podlag (Zakon o obrambi, podzakonski predpisi ...);

- zmanjšali smo število enot, predvsem poveljstev (npr. ukinili smo tri, načrtujemo ukinjanje še dveh brigadnih poveljstev);

- zmanjšali smo število objektov in opravili koncentracijo sil in sredstev $\mathrm{v}$ perspektivne objekte, ki jih tehnično opremljamo (smo pri koncu programa);

- pripravili smo nov koncept usposabljanja in izobraževanja, prilagojen profesionalni vojski. Vzpostavljamo organizacijo SV po sprejetem konceptu usposabljanja (oblikovali smo Center za usposabljanje Vipava). Sprejeli smo organizacijske ukrepe za usposabljanje prostovoljne - pogodbene rezerve v gorskem bataljonu;

- v enotah, kjer se je postopoma zmanjševalo število nabornikov, izvajamo usposabljanje poklicne sestave za prevzemanje nalog v prihodnji poklicni strukturi (splošno in specialistično vojaško usposabljanje);

- posebej smo obravnavali varovanje objektov: zmanjševanje števila objektov, tehnično opremljanje, spremembe načina skladiščenja.

Dodatni elementi, ki so vplivali na odločitev za predčasno opustitev služenja vojaškega roka, so:

- z bližanjem zakonskega roka, ko bo treba opustiti obvezno služenje vojaškega roka, je bilo vedno težje zagotavljati dovolj nabornikov, načrtovano število smo sicer še lahko zagotovili;

- vojaški obvezniki, ki so prihajali na služenje vojaškega roka, so bili vse manj motivirani za služenje, število vlog za uveljavljanje ugovora vesti je počasi naraščalo;

- enote SV so se prilagajale stanju, ko ne bo več vojakov na služenju. Nadaljnja razporeditev vojakov nabornikov v enote SV bi zanje predstavljala dodatno breme in tako bojna pripravljenost SV ne bi rasla.

Analizirali smo zahteve za oblikovanje intervencijskih sil za posredovanje na objektih SV in MO RS ter v nalogah zaščite in reševanja. Podrobneje smo proučili naloge dodatne zaščite, varovanja in obrambe objektov SV in MO RS, zaščite in varovanja poveljstev in oseb, premikov na ozemlju RS ter mobilizacije. Ugotovili smo, da z ustrezno organizacijo sistemov dežurstev ter izvedbo nalog izpolnimo postavljena merila za opravljanje teh nalog. V dosedanjem popolnjevanju SV kot dela procesa profesionalizacije oziroma projekta PROVOJ smo zaposlili preko 1600 poklicnih vojakov in več kot 250 kandidatov za vojake, skupna sestava SV pa je narasla na več kot 6300 pripadnikov. Usposobljenost poklicnih vojakov in njihova opremljenost z opremo Bojevnika 21. stoletja sta bistveno boljši, trenutna učinkovitost v primerjavi z naborniško vojsko ni primerljiva. S promocijskimi dejavnostmi zagotavljamo dovolj kandidatov za poklicne vojake in podčastnike. Z navedenim številom zaposlenih, $\mathrm{s}$ približno 400 pripadniki pogodbene rezerve ter $\mathrm{z}$ obvezno rezervo, opredeljeno $\mathrm{z}$ zakonom, smo sposobni opraviti naše sedanje naloge. 
Vojaki na služenju vojaškega roka so v mobilizacijskem sistemu predstavljali vir za dopolnjevanje VE in opravljali manjše pomožne naloge. Zaradi ugodnih ocen varnostne situacije opustitev obveznega služenja vojaškega roka ne pomeni zmanjšanja mobilizacijske pripravljenosti vojske. Ponovno opredeljujemo mobilizacijo vojske in pripravljamo novo navodilo za izvajanje. Mobilizacijo kot pojem povezujemo s pripravljenostjo enote za izvajanje dodeljene naloge in ne več zgolj z oblikovanjem enote.

V mobilizacijskem sistemu načrtujemo spremembe mobilizacijskih časov-podaljšanje na 30, 90 in 180 dni. Tako se približujemo standardom in merilom v zavezništvu. Te spremembe ne pomenijo, da bo mobilizacija lažja, ampak bo celo zahtevnejša. Načrtujemo manjše število subjektov - enot, enote bodo imele drug namen in drugačne naloge, načrtujemo tudi logistične spremembe v sistemu mobilizacije.

\section{Varovanje objektov}

Z zmanjševanjem števila skladišč orožja, streliva in MES sta se občutljivost in pomen posameznih skladišč povečala. Zato smo uvedli tehnično varovanje in varovanje s stalno sestavo. To nalogo je opustitev naborniškega sistema najbolj prizadela oziroma je bila na tem področju sprememba po opustitvi služenja najbolj očitna.

Potrebno število moštva za varovanje smo z organizacijskimi in tehničnimi ukrepi zmanjšali. Na večini objektov je tehnično varovanje že ustrezno vzpostavljeno, da ni treba vsake točke in objekta vedno nadzorovati z ljudmi. V letošnjem letu opremljamo s sistemom tehničnega varovanja tudi nekaj dodatnih skladišč. Varovanje je osredotočeno na kritične točke in ne več na pokrivanje prostora, varovanje vojašnic izvajamo s tehničnim varovanjem posameznih zgradb in fizičnim varovanjem varnostno nadzorno službo, varovanje skladišč pa s celovitim tehničnim varovanjem, operaterji in patruljami v objektih. Strelišča, vadišča in izpraznjene neperspektivne objekte bomo varovali z občasnimi obhodi.

S temi ukrepi smo moštvo za varovanje objektov zmanjšali na največ 100 (zaradi različnih zahtev patruljiranja) pripadnikov poklicne sestave $\mathrm{v}$ eni izmeni oziroma 440-500 pripadnikov vojske za zagotovitev izmenskega dela. Še naprej zmanjšujemo število objektov, ki so potrebni varovanja, kar je način za nadaljnje zmanjševanje teh sil, in nadaljujemo uvajanje celovitega tehničnega varovanja vseh skladišč in ogroženih objektov v vojašnicah, s čimer bomo izboljšali predvsem kvaliteto varovanja. Uporabljali bomo tiste rešitve, ki bodo zagotavljale potrebno varnost ljudi in premoženja ter ne bodo preveč obremenjevale pripadnikov Slovenske vojske.

\section{Usposabljanje}

Usposabljanje vojakov na služenju vojaškega roka je potekalo na 18 lokacijah po Sloveniji: v Ljubljani (Vojašnica Franca Rozmana Staneta in Vojašnica Šentvid), na Vrhniki (Vojašnica 26. oktober in Vojašnica Ivana Cankarja), v Kranju, Bohinjski 
Beli, Postojni, Vipavi, Ilirski Bistrici, Novem mestu, Cerkljah ob Krki, v Celju, Mariboru, Ptuju, Slovenski Bistrici, Murski Soboti, Pivki, Ankaranu, občasno pa tudi v drugih objektih.

Temeljno usposabljanje je $\mathrm{v}$ zadnjih dveh letih potekalo na štirih lokacijah. To so Maribor, Ptuj, Novo mesto, Bohinjska Bela, specialistično usposabljanje pa v centru in enotah SV na devetih lokacijah: Cerklje ob Krki, Maribor, Slovenska Bistrica, Vipava, Pivka, Ljubljana (FRS), Ankaran, Kranj, Vrhnika. Temeljno (TVSU) in osnovno (OVSU) vojaškostrokovno usposabljanje potekata v Centru za usposabljanje (CU) Vipava in Centru vojaških šol (CVŠ). Enote, popolnjene s profesionalno sestavo (1. BR), izvajajo usposabljanje skladno z vsebinami iz že narejenih načrtov in programov za usposabljanje vojakov (predvsem urjenje enot), $v$ enotah, ki so do sedaj izvajale usposabljanje vojakov na služenju vojaškega roka, pa potekata specialistično in splošno usposabljanje.

Usposabljanje vojakov na prostovoljnem služenju vojaškega roka bo potekalo v štirih vojašnicah (Bohinjska Bela, Novo mesto, Murska Sobota, Postojna), nanj je SV organizacijsko in kadrovsko že pripravljena. Zagotovili smo 1150 ležišč v osmih vojašnicah, z možnostjo povečanja še v dveh. V letu 2003 se usposablja pogodbena rezerva v 1. GORČ, v prihodnjem letu pa načrtujemo usposabljanje pogodbene rezerve $\mathrm{v}$ 9. RBR ZO, 18. BRBKO in v 132. GORB oziroma v petih vojašnicah (Bohinjska Bela, Novo mesto, Postojna, Maribor, Vrhnika).

Z opustitvijo obveznega služenja vojaškega roka ustvarjamo pogoje za zmanjšanje števila objektov za usposabljanje, enotam pa omogočamo, da je kvalitetnejše (splošno in specialistično), kar do sedaj v večini primerov ni bilo mogoče, saj so se usposabljanja ponavljala $\mathrm{z}$ novimi naborniki (usposabljanje nabornikov smo zaključili s tretjo fazo in se znova vračali $\mathrm{v}$ prvo fazo). Z uvajanjem kategorije poklicnih vojakov izpolnjujemo tudi pogoje za opremljanje vojske z zahtevnejšo vojaško opremo in oborožitvijo iz temeljnih razvojnih programov.

Z ukinitvijo naborniškega sistema v SV in prehodom na poklicno vojsko spreminjamo organizacijo dežurnih služb. Organizacija bo zaradi neprekinjene pripravljenosti sistema vodenja in poveljevanja temeljila na operativnem dežurstvu in dežurstvu $\mathrm{v}$ vojašnicah, vanj bodo vključeni elementi nadzora dela in izpolnjevanja nalog (vključno z zavarovanjem) vseh enot v vojašnici. S tem načinom smo zmanjšali število dežurnih služb in razbremenili pripadnike stalne sestave prevelikega števila nalog.

\section{Infrastruktura}

SV je od večjih objektov upravnemu delu MO RS za nadaljnji postopek že predala vojašnici v Logatcu in Ilirski Bistrici ter nekatere manjše objekte in skladišča: vadišče Kostanjevica na Krasu, vojašnico v Velikih Blokah, objekt Jedinščica v Novem mestu, skladišče Talčji Vrh pri Črnomlju ter skladišča Sevnica, Dovjež, Borovec v Kočevski Reki in Slovenske Konjice. Izpraznjena sta tudi objekta Lokve in Moretini, načrtujemo še izpraznitev in predajo dveh vojašnic. Bistvena ugotovitev 
te analize je, da z nadaljevanjem služenja vojaškega roka do sredine leta 2004 ne povečujemo obrambnih sposobnosti države in kvalitete opravljenih vojaških nalog. Z opustitvijo napotitve na služenje vojaškega roka pred predvidenim rokom (natančneje - v roku, saj je zakonska dikcija jasna: do 30. junija 2004) pa pridobimo predvsem čas za temeljito prestrukturiranje vojske, uvajanje novih standardov in pripravo za uresničevanje namenskih nalog.

\section{PREDLOG MINISTRU ZA OBRAMBO O OPUSTITVI VPOKLICA OKTOBRSKE GENERACIJE VOJAKOV}

Pri razumevanju navedene problematike je treba ponovno opozoriti na že znano dejstvo in trditev, da je vojska orodje v rokah politikov in da je v vsaki demokratični družbi vojska pod civilnim nadzorom. Generalštab kot najvišji organ vodenja in poveljevanja je seveda stalno analiziral razmere in stanje v Slovenski vojski, presojal razvoj varnostne situacije in mednarodnih dogodkov ter predlagal različne rešitve. Niti Generalštab niti Slovenska vojska kot celota pa nista popolnoma samostojni instituciji, ki bi lahko delovali mimo našega sistema državne ureditve ter predlagali in dobili prav vse, kar bi po svoji presoji potrebovali. Take razmere in tako razmerje moči smo v naši zgodovini že poznali, poznamo tudi primere v svetu, ki za nas nikakor ne morejo biti sprejemljivi. Naše zahteve in predlogi so seveda deležni pozornosti in upoštevanja, še zdaleč pa ni nujno, da so v sistemu demokratične ureditve sprejeti v predlagani obliki.

Zato smo predloge za postopno opustitev služenja vojaškega roka poslali $\mathrm{v}$ parlamentarno obravnavo. Po sprejemu sprememb in dopolnil Zakona o obrambi in Zakona o vojaški dolžnosti je bilo treba ponovno analizirati naloge vojske, časovne roke in vire za uresničitev teh nalog ter poiskati $\mathrm{v}$ teh razmerah ustrezno različico optimalnih pogojev za nadaljnji razvoj. Kot pogoj za opustitev napotitve na služenje vojaškega roka smo morali izpolniti nekatera kadrovska in organizacijska merila, tako da sem lahko predlagal ministru za obrambo opustitev vpoklica oktobrske generacije vojakov nabornikov. Menim, da so $\mathrm{v}$ danem trenutku varnostne razmere, sedanje in prihodnje naloge Slovenske vojske ter predvideni čas za usposobitev novih enot narekovali to odločitev in da sta trenutek in način ustrezala sprejetju te odločitve.

\section{PREDNOSTNE NALOGE RAZVOJA SV}

Varnostno okolje in predvsem načini, kako bomo v bližnji in daljni prihodnosti uresničevali z zakonom o obrambi določene naloge, se hitro spreminjajo. Skupaj z upravnim delom Ministrstva za obrambo smo pripravili strateški pregled obrambe in osnutek splošnega dolgoročnega programa razvoja in opremljanja SV do leta 2015 ter jih med nastajanjem tudi usklajevali z drugimi dokumenti in z našimi zavezniki. Prihodnost v okviru zavezništva presojamo kot zanesljivo in stabilno, smer našega razvoja pa kot jasno določeno in zapisano. Gremo v zavezništvo, postajamo njegov del in gradimo profesionalno vojsko. 
Morebitne spremembe varnostnega okolja bodo seveda zahtevale ponovno presojo situacije in ponovno prilagajanje in odzivanje na varnostne izzive in morebitne nove grožnje naši suverenosti in nedotakljivosti ter miru in stabilnosti. Majhna in sodobna vojska se bo takšnim spremembam in novim zahtevam zlahka prilagajala. Izkušnje nas učijo, da to delo ni nikoli končano. Nadaljevanje procesa profesionalizacije vse do konca tega desetletja, približevanje zavezniškim strukturam in vključevanje vanje ter gradnja strukture, ki bo ustrezala zahtevam časa in nalog vojaške obrambe, so tri temeljne sestavine obrambnih reform.

Področij dela, na katerih bi lahko izboljšali stanje, je veliko. Kritična presoja lastnega dela nam bo odgovorila na vprašanje, kje in kaj bi lahko bolje naredili. Opravimo to profesionalno. Dokler zaznavamo odstopanja, smo kritični in se razvijamo v pravi smeri, ne smemo pa prezreti, da smo veliko dobrih stvari že napravili.

Sklep Razlika med nami in nam primerljivimi državami je več kot očitna. Druge države so že imele svojo vojsko, ki jo je bilo treba zmanjšati, preoblikovati in modernizirati (Madžarska, Avstrija, Češka). V zadnjem desetletju je večina vojsk doživljala spremembe, ki so bile naravnane predvsem na nove oblike ogrožanja in nove varnostne izzive v okolju. Mi smo začeli Slovensko vojsko in njene posamezne elemente leta 1991 šele graditi na temeljih in tradiciji, ki jih je postavila teritorialna obramba za varnostne izzive zadnjega desetletja prejšnjega stoletja. Zelo splošno rečeno, drugi morajo odpuščati, mi pa številčno stanje poklicne sestave povečujemo. Prehod drugih, številčnejših vojsk na druge načine popolnjevanja je počasnejši iz povsem preprostega razloga, ker je v kratkem času nemogoče zamenjati naborniški kontingent trideset ali štirideset tisoč vojakov s pogodbenimi ali poklicnimi vojaki. Opustitev služenja vojaškega roka je samo eden od korakov profesionalizacije Slovenske vojske. Nadaljevali bomo popolnjevanje s poklicnimi vojaki in pogodbeno rezervo. V projektu PROVOJ smo zapisali, da bo proces profesionalizacije trajal do leta 2010. Do takrat bomo poklicno opravljali svoje naloge, se modernizirali, kvalitetnejše usposabljali in postajali učinkovitejši. Posamezniki že sedaj odlično in profesionalno opravljajo svojo dolžnost, nekatere enote bodo v tem procesu hitreje dosegle profesionalnost. Naš cilj pa je posameznikom, pripadnicam in pripadnikom vojske, enotam in poveljstvom z opremljanjem, organiziranjem, pogoji dela in bivanja ter visokimi standardi usposabljanja omogočiti postopen prehod od povprečnosti do popolne profesionalnosti.

Danes potrebujemo novo vojsko za novo tisočletje. Z jasno referendumsko odločitvijo o našem članstvu v Evropski uniji in severnoatlantskem zavezništvu smo si izbrali pot skupne, kolektivne obrambe, za katero pa koncept splošnega ljudskega odpora in družbene samozaščite v največjem delu ni primeren. »Pogajanja« z zavezništvom še trajajo, vendar je že sedaj skoraj popolnoma jasno, katere dele vojske bomo sami razvijali, kakšen bo naš prispevek k zavezništvu in kaj lahko mi pričakujemo od skupne obrambe. 
Smo relativno majhna država z razmeroma majhno vojsko. Znana je misel, da dober poveljnik svoje slabosti spremeni v prednosti; naša relativna majhnost nam seveda ponuja večje možnosti hitrejšega odgovora in hitrejšega prilagajanja novim varnostnim izzivom, takšno prednost je seveda treba temeljito izkoristiti. Uspešno smo se znali organizirati za nalogo osamosvajanja, uspešno smo odgovorili izzivom zadnjega desetletja minulega stoletja in znali se bomo organizirati, opremiti in usposobiti za prihodnje izzive. Ne gre dvomiti o naših odločitvah in uspešnosti profesionalizacije, približevanju in integraciji ter preoblikovanju Slovenske vojske, te naloge bomo zanesljivo opravili. Velja se potruditi, da jih opravimo kot poklicni vojaki, podčastniki in častniki ter kot profesionalci na vojaškem področju, z odliko. Merilo naše uspešnosti bodo vojaške zmage in ugled, pridobljen z odlično opravljeno nalogo.

Ob vsem pa velja dodati, da naborniškega sistema ne smemo pozabiti, ne samo zaradi zakonskega določila, ki ob morebitni izjemni ogroženosti omogoča ponovno uvedbo tega sistema, temveč zaradi spoznanja, da nam je omogočil osamosvojitev. Večina se nas je srečala z naborništvom in ima takšne in drugačne, dobre pa tudi slabe spomine na te mesece ali ta leta. Rad bi se zahvalil vsem generacijam, od prvih iz Peker in $\mathrm{z}$ Iga, do zadnje, ki so na ta način prispevale k obrambni naše skupne domovine. 